\title{
"LUGARES QUE TIENEN UNA HERIDA QUE SANGRA": LAS GEOGRAFÍAS INTERIORES DE FERNANDO VALVERDE
}

"Places with a bleeding wound": Fernando Valverde’s internal geographies

\author{
LAURA SCARANO \\ UniVERSIDAD NAGiONAL DE MAR DEL Plata (ARGENTINA) laurarosanascarano@gmail.com
}

\author{
RECIBIDO: 18 DE DICIEMBRE DE 2017 ACEPTADO: 11 DE FEBRERO DE 2018
}

Resumen: Fernando Valverde (Granada, 1980) edita en 2016 el volumen Poesía (1997-2017), donde reúne su poesía completa hasta la fecha: Viento favorable (1997-2002), Razones para buir de una ciudad con frío (2004), Los ojos del pelicano (2010) y La insistencia del daño (2014). Analizamos aquí la constitución de una peculiar cartografía poética, que cumple un papel axial: conecta territorios y culturas bajo una misma matriz existencial, configurando una geografía interior basada en la apropiación subjetiva de ciudad y naturaleza. Esta conversión del "lugar" en "espacio practicado" (Michel De Certeau) se realiza aquí a través de dos dispositivos: el mapa y el viaje. Valverde pone en marcha su poesía con la metáfora del "andar": logra la apropiación presente del espacio (natural pero sobre todo urbano) por un yo que selecciona y construye su itinerario en la confluencia de la experiencia histórica pública y privada. Espacio y sujeto son pues las dos coordenadas que abordaremos como caras de una misma moneda, entendiendo ambas como categorías con un espesor cultural y epistemológico, que refunda la ancestral figura del bomo viator, dentro de un imaginario urbano globalizado, afín a lo que es ya un fenómeno de época: "el giro espacial".

PALABRAS CLAVE: Fernando Valverde, giro espacial, geografía interior, poesía de la incertidumbre.

ABSTRACT: In 2006 Fernando Valverde (Granada, 1980) published the volume Poesía (1997-2017), where he collected his complete poetry until that date: Viento favorable (1997-2002), Razones para huir de una ciudad con frío (2004), Los ojos del pelícano (2010) and La insistencia del daño (2014). We analyse here the establishment of a peculiar poetic cartography, which plays a crucial role: it connects territories and cultures through the same existential matrix, shaping an internal geography based on the subjective appropriation of city and nature. This conversion of the "place" into a "practiced space" (Micheal De Certeau) is realized here though two devices: the map and the travel. Valverde initiates his poetry with the metaphor of "walking": the present appropriation of the natural space, but above all the urban space, is achieved by an authorial voice who selects and builds his itinerary in the confluence of the historic experience, both public and private. Space and subject are, thus, the two coordinates we will deal with, considering them as two sides of the same coin, conceiving them as categories with a cultural and epistemological thickness, which consolidates the ancestral concept of homo viator, within an urban globalized imaginary, closest to something that has already become a phenomenon of our age: "the spatial turn".

KEYWORDS: Fernando Valverde, spatial turn, internal geography, poetry of uncertainty.

Scarano, Laura.

“Lugares que tienen una herida que sangra': las geografías interiores de Fernando Valverde".

Kamchatka. Revista de análisis cultural 11 (Julio 2018): 289-310

DOI: 10.7203/KAM.11.11218 ISSN: 2340-1869

Monográfico LECTURAS DEL DESIERTO: NUEVAS PROPUESTAS POÉTICAS EN ESPAÑA 
En este monográfico, que focaliza la poesía de autores nacidos a partir de 1980, cabe destacar el rol peculiar del granadino Fernando Valverde, quien ve la luz precisamente ese año. ${ }^{1}$ En 2016 editará en Visor el volumen Poesía (1997-2017), donde reúne tres poemarios completos: Razones para buir de una ciudad con frío (2004, RHCF), Los ojos del pelicano (2010, OP), La insistencia del daño (2014, ID) y algunos poemas iniciales (Viento favorable, 1997-2002, VF). ${ }^{2}$ Digo peculiar porque es uno de los pocos autores preocupados por instaurar un diálogo interoceánico entre ambas orillas del español, además de gozar de un reconocimiento que trasciende las fronteras peninsulares.

Uno de los fundamentos de esta proyección es su pertenencia al movimiento Poesía ante la incertidumbre, del que fuera cofundador en 2011, firmando una especie de "manifiesto" de presentación del grupo titulado "Defensa de la poesía" (Alí, 2011), que profundizarán sus miembros un año después con el subtítulo "Un viaje a la esencia" (Alí, 2012). La primera edición de esta "Antología de nuevos poetas en español" apareció en Visor de España y se replicó en México, Colombia, Argentina, Chile, Perú, El Salvador, Nicaragua, Bolivia, Ecuador, Estados Unidos e Italia, con una nómina intercontinental. ${ }^{3}$ Subrayaban allí los poetas reunidos la necesidad de reivindicar un espacio común, en un imaginario desterritorializado, el del panbispanismo, similar al que soñara Juan Ramón Jiménez desde América o Francisco Ayala en su exilio argentino, pero en formato siglo XXI. Y para nombrar su poética adoptaron una categoría cultural, la del poeta enfrentado al abismo de la incertidumbre: de verdades, de sentidos, de valores. Ante ese desconcierto, defienden la función de la poesía para construir certezas, aunque sean modestas y precarias, de decisivo tono menor, anti-profético y huyendo de la solemnidad y los fundamentalismos: "La poesía puede arrojar algo de luz para alcanzar algunas certidumbres necesarias" (2011: 7). ${ }^{4}$ Hasta hoy, Valverde sigue apoyando firmemente este credo colectivo:

Sigo totalmente comprometido con todo lo que significa Poesía ante la incertidumbre. Lejos de haberme distanciado, con los años me he reafirmado en lo que planteamos en 2011.

\footnotetext{
${ }^{1}$ De vocación periodista, es doctor en Literatura y Licenciado en Filología Hispánica, Antropología Social y Cultural y Filología Románica por la Universidad de Granada. Trabaja actualmente como profesor universitario en Estados Unidos. Ha sido organizador hasta hace poco del FIP (Festival internacional de Poesía de Granada). Con la recopilación de su obra en Poesía (1997-2017) repasa una trayectoria intensa y fecunda. Su último libro, La insistencia del daño (2014) ha permanecido varios meses en el primer lugar de las listas de ventas españolas y ha recibido el Premio a Libro del año del Latinoamerican Writers Institute de la Universidad de Nueva York. Fue acreedor de un Grammy, junto al cantaor Juan Pinilla (Valverde, 2017, s/p) por su trabajo de fusión del flamenco y la poesía, y en 2015 la Asociación Andaluza de Escritores y Críticos Literarios le concedió el Premio Andalucía de la Crítica.

${ }^{2}$ Utilizaremos las mencionadas abreviaturas de cada libro en las citas correspondientes.

3 Los integrantes fundacionales son Alí Calderón (México), Jorge Galán (El Salvador), Francisco Ruiz Udiel (Nicaragua), Andrea Cote (Colombia), Ana Wajszczuk (Argentina) y Raquel Lanseros, Fernando Valverde y Daniel Rodríguez Moya (España). En las siguientes ediciones se van agregando autores de otras nacionalidades hasta sumar once países en total; se añaden el colombiano Federico Díaz-Granados, el ecuatoriano Xavier Oquendo Troncoso, la salvadoreña Roxana Méndez, el boliviano Gabriel Chávez Casazola, el argentino Carlos Aldazábal, el peruano Juan Carlos Yrigoyen, la chilena Damsi Figueroa, la palestina Natalie Handal, etc.

4 Señala con acierto Morales Lomas que para el grupo "la incertidumbre [es] una herramienta paradigmática en la que anclar una manera de inmiscuirse en el mundo y no ser ajenos a su evolución” (2017: 128).
} 
La poesía no es un artificio, la poesía está en el mundo y es patrimonio de todos los seres humanos, no se trata de un lenguaje de intelectuales que ha acabado encerrado en los departamentos de las universidades. La poesía es la forma de comunicación más noble y humana porque nos sirve para hablar de lo que nos resulta complicado porque nos duele o nos avergüenza, de cosas tan íntimas como el miedo, la fe, el amor, la muerte, la decepción o el fracaso. (2017, s/p)

En El canon abierto. Última poesía en español, editado por Remedios Sánchez García y Anthony Geist, cerca de doscientos investigadores eligieron a los poetas de mayor relevancia surgidos después de 1970, siendo Fernando Valverde el más votado. Representante señero de ese grupo con vocación transatlántica, los define Remedios Sánchez García como creadores de una "literatura humanista de corte coloquial comprometido", que construye un discurso "legible" y "conversacional", buscando "en la palabra un refugio frente a las incertidumbres del mundo contemporáneo" (2015: 39-41), “con una voz potente en Hispanoamérica y España conformada por voces múltiples y críticas con la realidad social” (2015: 53). La poesía debe reivindicar su capacidad de comunicar y conocer, pero sin arrogancia, admitiendo sus límites, sin absolutizaciones. "Comunicación”, “emoción”, "humanización”, su programa poético conduce a la figura del lector, para establecer lazos comunes y promover proyectos comunitarios (Scarano, 2016: 272).

Santiago Espinosa vislumbra en este colectivo la constitución de una comunidad de lectura que reúne varios caminos, superadores de las anteriores dicotomías entre claridad vs. misterio o irracional vs. coloquial, y que vuelve a emparentar las dos márgenes del Atlántico, distanciadas desde hace décadas (2016: 317). El propio poeta en una entrevista, a la pregunta: "Es habitual de países latinoamericanos, ¿qué le ha aportado su cercanía a la poesía de esa tierra?”, responde:

Mucha conciencia. Por un lado la oportunidad de ver un mundo diferente en mi mismo idioma con el que poder establecer un diálogo complejo. Por otro, una nueva tradición poética que llegó hasta mí de forma inesperada llena de diferentes acentos y ritmos para la poesía. Hoy me siento especialmente influido e inspirado por sus poetas, de quienes trato de asimilar una música que me interesa más que la de la poesía española. Al margen de la poesía, Latinoamérica me ha conmovido muchas veces por su forma de reponerse de las desilusiones y de construir luz entre las tinieblas. Como escribió Hölderlin, donde crece el peligro, crece también aquello que puede salvarnos. $(2017, \mathrm{~s} / \mathrm{p})$

Valverde defiende el carácter dialógico de la poesía, su intrínseca vocación social, desde una matriz que aúna experiencia, meditación y cuidada elaboración formal. Si cabe algún rótulo aquí podríamos hablar de una poética del lector, centrada en los efectos sociales del discurso. De hecho en una entrevista reciente sostiene: "Con el tiempo uno aprende que en el poema hay que dejar un espacio que pueda habitar el lector", "He dejado de ponerme en el lugar de mí mismo para disfrutar la diversidad que supone ponerse en el lugar de otro" (2017, s/p). El lenguaje no ha dejado pues de ser un instrumento poderoso para elaborar sentidos compartidos, con una nueva conceptualización del compromiso, que nos recuerda la consigna del "oficio como ética" lanzada 
por "la otra sentimentalidad" granadina en los 80 y reelaborada por Luis García Montero, el padre "fuerte" de Valverde en las dos últimas décadas. ${ }^{5}$

El propio poeta, en el Prólogo que inicia su poesía reunida titulado "El lugar de la poesía", resume algunas notas distintivas que conforman un programa de lectura, y nos servirá de pórtico para avanzar en sus poemarios compilados. Razones para buir de una ciudad con frío "está lleno de esa intuición por la pérdida de un mundo irrecuperable, el de la infancia", con poemas que pretenden desertar de "el frío que los años van dejando/ detrás de la palabras", como reza uno de sus versos. Los ojos del pelícano retrata el modo de pescar de estas aves en un pueblo costero de Nicaragua, pues "planean hasta avistar su presa y de repente se dejan caer en picado. El golpe contra el agua es brutal" y "muchos pelícanos mueren ciegos, perdidos en el horizonte". Metáfora luminosa y trágica -que condensa la historia de su madre- para poetizar "la manera en que los sueños de la gente normal se estrellan una y otra vez contra la realidad", desde un sentimiento ante el dolor, que se acrecienta en el último libro. En La insistencia del daño el poeta es "testigo de la herida que el mundo comparte, del sufrimiento que nos iguala". Por eso afirma que "si la poesía puede contribuir a un mundo mejor es porque nos ayuda a comprender el dolor de los otros" (Valverde, 2016:11-12).6

En nuestra lectura advertimos que una cartografía muy especial es diseñada a lo largo de sus libros, la cual pasaría quizás desapercibida para el lector desatento, pero que cumple un papel axial: conecta territorios y culturas bajo una misma matriz existencial, configurando una geografía interior basada en la apropiación subjetiva de ciudad y naturaleza.

En otros trabajos he intentado analizar el decurso teórico de la conceptualización urbana y vale la pena incluir aquí algunas premisas (Scarano, 1999).7 La literatura sobre la ciudad se establece entre dos condiciones pre-discursivas: el espacio material y la mirada subjetiva. El espacio se presenta con la estructura de un topos, una trama densa cercana al palimpsesto, que acumula índices o marcas léxicas (objetos, lugares, hechos, nombres), modos del habitar, actores sociales tipificados, toponimias, historias o micro-relatos propios de la vida urbana, etc. Pero a la

\footnotetext{
5 Jorge Bocannera, en una reseña titulada "Entre el furor y la nostalgia", no sólo inscribe a Valverde en la tradición española de Machado, Ángel González y García Montero, sino que lo emparienta con el chileno Jorge Teiller y el cubano Eliseo Diego, especialmente en el tratamiento del pasado infantil y “el naufragio del ser" (193).

${ }^{6}$ José Enrique Martínez, en una acertada reseña que titula "Un puente entre dos orillas", subraya que "la emoción” y un "acusado sentido rítmico" (2017, s/p) resultan ser la médula de su poesía entera, y se ve reflejada en estas afirmaciones de su Prólogo, que configuran una verdadera poética.

${ }^{7}$ Las mitologías de la ciudad (desde la Atenas apolínea a la ciudad errante del Caín bíblico) y sus diversas etimologías (polis, urbs, civitas) fueron el punto de partida para un pensamiento sobre lo urbano, que progresivamente ha desplazado el eje de estudio de su naturaleza objetiva y territorial, a las formas concretas en que el hombre la vive y experimenta. Michel de Certeau, Richard Sennet, Marc Augé, Zygmunt Bauman en Europa o los latinoamericanos Néstor García Canclini, Jesús Martín Barbero y Beatriz Sarlo entre otros, coinciden en que hoy "la ciudad se piensa simultáneamente como resto de una modernidad pintoresca y bastión de una modernidad opresiva", como afirma Adrián Gorelik (21). La ciudad como texto material es abordada hoy de manera integral desde la perspectiva de los imaginarios urbanos, donde confluyen diversas disciplinas -sociología, antropología, historia, filosofía, arquitectura y urbanística- que han enriquecido el estudio de esta categoría, dotándola de espesor ideológico y densidad conceptual.
} 
vez, se constituye como gesto ideológico de un sujeto que dice yo, desde una mirada que lo compone y representa. En el discurso urbano, espacio y mirada parecen homologarse, ya que sus enunciados comprometen una posición de sujeto. Por un lado, la ciudad se deja hablar por un sujeto: se verbaliza, y por el otro, el sujeto se espacializa y objetiva en ella su identidad emocional.

Es fundamental la reflexión que aporta Michel de Certeau, en su magnífico libro La invención de lo cotidiano, donde sostiene que la ciudad se transforma en espacio por intervención de los caminantes, a diferencia del lugar que "carece de la univocidad y de la estabilidad de un sitio propio" (1996: 129).8 ¿Qué ciudad se escribe hoy? No ya la "ciudad-panorama", sino la "ciudad de abajo", donde "viven los practicantes ordinarios", los "caminantes del texto urbano", que la escriben cotidianamente a través de usos y formas específicas de apropiación, mediante sus "artes de hacer". Importa la experiencia antropológica del habitar, que transforma los "lugares" en "espacios practicados", donde el ciudadano o el outsider dejan su huella, imprimen desvíos particulares a la norma común, crean sus "retóricas caminantes", sus "andares de ciudad" (1996: 104, 111). El caminante habita la ciudad con "sus artes de hacer" y convierte los recorridos en trayectos existenciales, por lo cual sus mapas urbanos expresan y reescriben vidas cotidianas que pueden representar a cualquier persona. Por eso, De Certeau habla de una "ciudad-palimpsesto", donde la subjetividad se vive como un "estar alli’" (dasein) que marca nuestra apropiación del lugar y su conversión en espacio (1996:121).

Veremos aquí cómo Valverde reescribe las ciudades que su personaje recorre en todo el planeta, con palabras que les otorgan un nuevo sentido, ya que estas ciudades escritas emergen como dobles alucinados de sus contrapartes, las ciudades reales que habita o visita, pero son aquellas las que se alimentan de los archivos del imaginario. Cuando encuentra un lugar, al habitarlo el hablante lo hace suyo, lo incorpora a su imaginario cultural, lo convierte en "espacio practicado", en el sentido de apropiado y le otorga entidad poética. Esta es una de las matrices más relevantes para la comprensión de su poesía, que no evita nunca el emplazamiento material, más bien lo refuerza, creando una cartografía existencial, afín a lo que parece ya un fenómeno de época y suele denominarse (emulando otros giros) como "the spatial turn" (el giro espacial).?

Valverde alterna dos dispositivos discursivos: los “mapas" y los "trayectos". Propone una poética del "andar". Pero, ¿qué es un "mapa”? Según cualquier diccionario de la lengua, es una representación geográfica de la tierra, o de parte de ella, sobre una superficie plana, de acuerdo con una escala; o bien un conjunto de elementos de un mismo tipo o categoría que tienen una distribución espacial determinada. Y ¿qué significa un “trayecto" (en el sentido de viaje, recorrido, itinerario)? Es el espacio que se recorre o que se ha de recorrer para ir de un lugar a otro. Michel

\footnotetext{
${ }^{8}$ De Certeau plantea un desplazamiento en el enfoque desde una ciudad-concepto a la de las prácticas vividas, la ciudad habitada "a ras del suelo" (1996: 109), especialmente en el cap. VIII, titulado "Andares de ciudad" de la III parte, "Prácticas de espacio", de su primer volumen subtitulado "Artes de hacer".

9 A partir de las nociones de cronotopo de Mijaíl Bajtín y de semiosfera de Iuri Lotman, se produjo una revisión del espacio como categoría ficcional y signo cultural y hoy asistimos a un auge de nuevas disciplinas como la Ecocrítica, que indaga acerca de los vínculos entre literatura y medio ambiente, y la Geocrítica que estudia la interacción entre los espacios ficcionales y los reales, o bien los Estudios Transárea y Transatlánticos. Desde estas nuevas coordenadas, ya no es posible entender el espacio como una estructura fija e inamovible, sino como parte de un proceso dinámico e incesante, que tiene que ver con múltiples lógicas regionales, nacionales, continentales y mundiales.
} 
De Certeau propone como dos instrumentos cognoscitivos los mapas (estáticos) y los recorridos (móviles): el estar abí del lugar frente al hacer humano del espacio transitado. Ir, deambular, pasear, caminar suponen un hacer que es, al sistema urbano, lo que el habla es a la lengua como código neutro (1996: 109). La ciudad y sus calles se transforman en espacio por intervención de sus caminantes; por eso sostiene que la ley del lugar es pues la de estar abí (lo tópico), mientras que la ley del espacio es la de las operaciones y acciones de sujetos históricos (1996:130) (lo topológico).

En esta poesía veremos cómo ambos conceptos se conjugan y solapan, convirtiéndose en principios constructivos del discurso: mapas y trayectos. Y en especial, cabe pensarla desde la inspirada afirmación inicial de Michel De Certeau: "La historia comienza a ras del suelo, con los pasos...", que son los que hacen efectivamente la ciudad (1996: 109). En esta experiencia del espacio se vuelven más pertinentes los "usos" que los objetos, los "relatos" que unen nuestra vida a los sitios que ocupamos (1996:129). Importa la inscripción del cuerpo que organiza el lugar en un aqui y un allá, los cuales representan los dos polos del babitar: la localización (configurada en el cuadro o el mapa) y el recorrido (o viaje), que expresa el movimiento, la acción del hombre al vivirlo, su práctica corporal (1996: 133).

Valverde pone en marcha su poesía con la metáfora del "andar": logra la apropiación presente del espacio (natural pero sobre todo urbano) por un yo que selecciona y construye su itinerario y le imprime su "estilo" particular. Nombres de secciones como "Las ciudades" (RHCF), "El viaje del mundo" (OP), "La tristeza en los mapas", títulos de poemas y versos repetidos como "ciudad con frío", "ciudad con lluvia", "ciudad dormida", "ciudad extraña", "ciudad enferma", y abundante vocabulario asociado: "paisaje", "país", "mundo", "lugar geométrico", "plazas", "puentes", "parques", "calles" configuran una familia léxica poderosa y recurrente que habilita nuestra hipótesis de lectura. A ello se suma la contundente figuración de un sujeto viajero, que recorre, deambula, visita, pasea, y da voz a sus itinerarios, contemplando y transformando esos espacios en geografías interiores.

Pero además, el granadino aquilata el topos bajtiniano por la indisoluble confluencia de tiempo y espacio (crono-topos), donde la humanidad se hermana en el dolor, la muerte, la nostalgia... Traza un mapa de la tristeza, parafraseando el título de una de las secciones de su último libro, "La tristeza en los mapas" (ID). En una entrevista, a la pregunta: "Su poesía está plagada de referencias geográficas y de viajes. ¿Está la poesía en el lugar o en el viajero?”, responde sin dudar: "En el lugar como espejo del viajero" (2017, s/p). Espacio y sujeto son pues las dos coordenadas que abordaremos como caras de una misma moneda, entendiendo ambas como categorías con un espesor cultural y epistemológico, que refunda la ancestral figura del bomo viator, dentro de un imaginario urbano globalizado.

En esta cartografía podemos distinguir netamente dos dimensiones complementarias: el paisaje natural - como correlato del yo, pero también como materialidad planetaria-, y las ciudades, como argamasa de una identidad urbana compartida por fuera de las nacionalidades acotadas y legales. Y en consecuencia, una figuración nuclear será la del poeta flâneur, que se bifurca en dos direcciones: la del transeúnte urbano asociado a su entorno, observador, testigo, cómplice y crítico de sus lacras y zonas de confort. Y la del contemplador de la naturaleza, cuyos 
paseos lo implican de modo vital a una estructura de sentimientos que convierte esos mares y bosques en correlato objetivo de sus emociones.

En la reunión de sus textos primerizos, que lleva como título Viento favorable, impacta el poema "Cartas al mar desde la ciudad con lluvia" (VF 17-18), pues, si atendemos a nuestra propuesta, se relocaliza aquí al hablante en la frontera entre lo natural (mar) y lo urbano (ciudad). En cuatro secciones numeradas se instala una mirada teñida de melancolía: se contempla "el mar de invierno", metáfora de "todo lo perdido" que, por su "distancia", "deja de ser consuelo", sometido "a la crueldad del tiempo". La cifra "invierno"-"lluvia" es el presente que sumerge aquel mar añorado en el olvido: "días sin mar, así perdidos". Porque "se canta lo que se pierde" al decir de Machado, Valverde abre su joven voz a la memoria de una intimidad con el paisaje pasado que "la ciudad con lluvia" del hoy le ha arrebatado.

En este panorama de paisajes naturales el mar ocupa un rol preponderante. "El mar de invierno tiene/ la compleja nostalgia de los días de lluvia", sostiene en el poema "Mar de invierno", que se opone siempre a "el recuerdo del mar" en "el verano" (RHCF 64). En "Elegía para el mar", el hablante se sumerge en el aprendizaje marítimo que lo inició en el "sentido enfermizo de mi melancolía" y una "tristeza dulce". Transformado en correlato objetivo de ese hablante que fue niño y hoy vela su adultez, todos los predicados dirigidos al mar se resuelven en autoanálisis: "será porque hay ciudades sumergidas/ o tal vez porque el frío te ha vencido,/ el frío que los años van dejando/ detrás de las palabras...". El yo es ese mar que exhibe aquel "dolor sonámbulo", "el miedo a estar tan solo contra el mundo" (RHCF 67-68). Y uno de sus poemas últimos recupera esta nostalgia, sellando su identidad en ese paisaje marítimo: "Ya no existe aquel mar/ que fue verde en los ojos"; ante esa pérdida, confiesa su ambivalencia humana: "empiezo a parecerme a mis derrotas, / a mis viejos temores del tamaño del mar/ que todo lo humedecen,/ que son toda certeza y toda duda" (ID 231).

"La ciudad extraña" identifica esa identidad urbana fugitiva e inaprensible, como forma de pertenencia y experiencia de expulsión. De noche y en invierno, el hablante se encuentra consigo mismo sin máscaras que lo oculten: "Esta ciudad fue noche y fue diciembre.// Aquí ya todos saben quién soy yo, / difícil esconderme de mí mismo" (VF 25). Innumerables veces conecta la ciudad con el frío, la lluvia y el invierno, espesor climático del desamparo y una "melancolía ingrata y pasajera". Asume su condición de paseante urbano, impregnado de tristeza: "Me entiendo con el mundo pocas veces,/ si salgo a pasear, aunque tropiece/ con un recuerdo gris en las aceras" (VF 24). Frente a ese omnipresente tempus invernal, un poema titulado "Noches de verano", emplazado en una visión de la ciudad más benigna, abre en su recuerdo "un tiempo/ con parques, escondites y bullicio", "un niño enamorado en todas partes", aunque esas "noches de verano ya no existen,/ las dejé en algún lugar, seguí viviendo" (VF 26-27). Dice Morales Lomas, a propósito de la ciudad en Viento favorable, que

El reclamo de una ciudad ciega, una ciudad con su noche, sus sueños y sus lugares inhóspitos llenos de promesas y de tedio van moldeando al poeta y su existencia, sabiendo que el naufragio puede ser un lugar donde acudir. Una ciudad dormida de la que acabará yéndose el poeta, [...] un camino para hacer de la existencia un proceso de arquitectura vital" (2017:131). 
La nieve es emblema también de esta ciudad invernal en su próximo poemario, donde retrata en "Paisaje nevado" una estampa congelada, en la cual la lluvia predice la nevada y todo se transforma, como si fuera "un hecho solemne", "un momento de paz". Con los "labios morados" de frío, niños "sin libros ni carteras" deambulando por la calles, coches como "brasas", portales "de humo" y "gorros de colores por toda la ciudad", esta se reviste de los sentimientos del sujeto (RHCF 65). Se palpa la simbiosis por la cual el fenómeno meteorológico de la nieve sacude la monotonía urbana y muestra una vez más su peculiar hermandad con quien la mira. La ciudad se equipara a su contemplador.

Una sección completa de RHCF lleva como título "Las ciudades", precedida por un epígrafe de Federico García Lorca de Poeta en Nueva York, paradigma de una poética urbana que opone la civilización masificada de la metrópoli a la naturaleza avasallada en permanente peligro. Frente a las montañas "existen" los anteojos, declara Lorca como sistema antagónico. Pero su personaje -mitad testigo, mitad profeta-, declama en "New York. Oficina y denuncia" que no ha venido "a ver el cielo" (fin del epígrafe de Valverde), sino "la turbia sangre" (continúa Lorca). Por eso, el primer texto de la sección de este poemario de Valverde titulado "La ciudad", la describe sin nombre, como el topos urbano por antonomasia, desde esa tradición: "Es un espacio hostil", "un lugar geométrico" parecido al "desengaño" (RHCF 73-74). Un campo semántico cargado de afectividad la recorre como emblema del propio yo, espejo de sus "defectos y manías". El léxico urbano tipificado (semáforo, pisos, edificios, persianas, calles, restaurantes) se acopla a una de sus figuras arquetípicas, la del flâneur: "Solo los extranjeros / renuncian a la piel de las ciudades,/ los viajeros que tratan de escapar de las suyas". La ciudad es para ellos la cueva donde huir de su propia urbanidad en la condición de turista. $\mathrm{Y}$ al habitante permanente le ofrece "un hueco donde se esconda el aire/ mirando por encima de los pisos/ la quietud inocente de los días que corren".

A continuación, en esta sección se sucede una travesía por ciudades con nombre, topónimos reconocibles que esconden un guiño del autor, un mapa de sus itinerarios biográficos o imaginarios.

Un paseo por Europa nos lleva al texto titulado "En Amsterdam el sol se parece a un ahogado", ciudad habitada por "un silencio sordo", "un funeral de viento y avenidas", "puentes inútiles" y el mar "callado detrás de los diques", como si el cemento y la urbanización pudieran amordazar la naturaleza, en un ritual cercano al "magnicidio", en "Nieuwe Kerk" (RHCF 75). Otro texto titulado "Una araña me observa desde un viejo molino de viento en la ciudad de Brujas" nos sorprende con la interlocución a esa ciudad personificada, confluencia maravillosa de piedras, puentes e historia, donde "los turistas buscan fotos imposibles" y los paisajes se anudan con leyendas "de siglos y abandono" (RHCF 76-77).

De las tantas flexiones de esta geografía universal interiorizada, una se articula con una poética del compromiso, que en parte de su obra tiene como referente la tragedia de las guerras 
balcánicas, ${ }^{10}$ enhebrando ciudades de una zona devastada que conoció siendo corresponsal y donde la represión de escritores o las consecuencias de los totalitarismos lo impactaron profundamente. En una entrevista responde al respecto que "Si aprendemos a ponernos en el lugar del otro, si nos esforzamos por entender su diferencia y por comprender su dolor, habremos ganado una batalla decisiva al odio y a la desigualdad" (2017, s/p). Hablar de ellas es una forma de rescatarlas de la tragedia y el olvido, poseyéndolas por la poesía.

"Cinco elegías para un siglo" (RHCF 80-84) están dedicadas cada una a un autor que vivió la represión estalinista o las consecuencias de una tragedia bélica: Seifert, Sarajlic, Tsvetáyeva, Mandelshtam y Ajmátova, en enclaves espaciales precisos. La serie se presenta al modo de un fresco casi pictórico que recorre esa zona "caliente": Praga (República Checa, I), Sarajevo (Bosnia y Herzegovina, II), Elabuga (Rusia, III), Moscú (Rusia, IV) y la prisión de Las Cruces en Leningrado (V). Un friso de la Europa del Este castigada, donde la memoria histórica se hace presente en la conciencia social del hablante y da testimonio crudo del derrumbe o la caída, ese símbolo poderoso que entreteje desde siempre su poesía. Para Marisa Martínez Pérsico la caída es "uno de los temas predilectos del granadino, quien poetiza el mundo que quedó al otro lado del «telón de acero» y que se hizo más visible a Occidente tras la caída del Muro de Berlín en 1989”, "mientras ejercía su corresponsalía para el periódico español El País, que se extendió durante una década” (2017, s/p).

Cada escena de estas "Cinco elegías para un siglo" presenta un paisaje urbano, a veces identificado con una fecha histórica y un personaje, para denotar una atmósfera emocional y conciliar testimonio histórico con vivencia íntima y privada. A la manera de Brecht, la historia de lo menor escrita por debajo de próceres y batallas es la que conmueve y convoca a un consenso social, porque -como afirma su maestro Luis García Montero-, la intimidad es un territorio ideológico donde también pulsamos la temperatura de una época, un pueblo, una historia. En Praga, una madrugada de otoño de 1974, el poeta checo Jaroslav Seifert (1901-1986) piensa: "Esta ciudad es mía", mientras "busca/ un paisaje que pueda sostener/ dentro de algún poema". Pero el frío lo posee porque "ya no hay rincón oscuro donde arrugar pasiones./ Todo quedó en silencio" (80).

En Sarajevo, otra vez el frío penetra esta ciudad de noches interminables, donde "rara vez amanece" para el poeta bosnio Izet Sarajlic (1930-2002) (del que Valverde es traductor al español). Perteneciente a las Juventudes Comunistas yugoslavas, comenzó a escribir durante la II Guerra Mundial, después de que los “camisas negras" de Mussolini asesinaran a su hermano mayor. En el poema, la ciudad apropiada es la Sarajevo que fuera sometida a un cerco, desde el 5 de abril de 1992 al 29 de febrero de 1996. Y así la experimenta el poeta: "un día muy nuevo/ de

\footnotetext{
10 Nieves García Prados en su Tesis dedica un apartado a analizar el derrotero de los personajes de estas cinco elegías de Valverde y señala la "influencia que las experiencias vividas durante los viajes pueden marcar en la creación de un autor. En su caso, y de manera muy especial, han sido Los Balcanes los que se han quedado en su poesía como fruto de su experiencia personal. De este modo, la historia de un lugar remoto, de un territorio hostil, ha entrado en su obra, como también lo han hecho aquellos acontecimientos históricos sobre los que ha tenido conocimiento a través de la tradición escrita"; "Su trayectoria como periodista en el diario El País, donde ha trabajado durante una década, le reportó grandes experiencias en Los Balcanes, donde fue enviado especial para preparar un reportaje sobre las presencia de tropas españolas en Mostar" (2016: 189-190). Durante esa corresponsalía visita, en Bosnia y Serbia, algunos de los lugares candentes de la antigua Yugoslavia, como Srebrenica, Belgrado o Sarajevo.
} 
mil novecientos noventa y tres", "las noches son tan largas como el frío,/ tan largo es el dolor como las noches" (81). No obstante, rememora días sin granadas con su esposa Mikica, donde un hombre podía "levantarse temprano/ y coger margaritas con la mujer que ama" (RHCF 81).11

En Elabuga, un 31 de agosto de 1941, la poetisa rusa Marina Tsvietaieva (1892-1941) escribe "No pude más", con franca desolación a tres amigos, a modo de despedida, antes de suicidarse y cantar como "un mirlo/ que ha aprendido a volar" (82). ${ }^{12}$ En Moscú, el poeta judío nacido en Varsovia, Osip Mandelstam (1891-1938), perseguido por Stalin, pasea por los bulevares nocturnos y convierte su rabia en palabras, cuando "regresa a casa y siente frío" porque "el aire puede ser oscuro como el agua" (83).13

En la V elegía, el hablante en primera persona nos enfrenta con la imagen de la poeta Anna Ajmátova nacida en Ucrania, cerca de Odessa, mientras está prisionera por "los caprichos sucios de un tirano,/ en la cárcel horrible de Las Cruces" (84). Su más importante libro Réquiem es la respuesta poética al dolor de varias tragedias acumuladas: el fusilamiento de su primer marido, el arresto de su compañero Nikolái Punin en 1935, y la condena a un campo de trabajo en Siberia de su único hijo Lev. El yo del poema de Valverde se abre con una confesión: "Últimamente pienso en Anna Ajmátova", y recrea su ahogo espiritual: "su temor de madre", "su justa certeza de haber vivido un tiempo/ que quiso perseguirla", para consustanciarse con esos "ojos de una mujer triste".

Todos estos seres fueron perseguidos políticos, muertos en vida y sujetos de una historia de derrotas; no obstante levantan su testimonio en una poesía elegíaca que lucha tenazmente contra esas murallas invisibles pero fatídicas que sellan sus tristes finales.

Otra flexión urbana nos lleva al buceo interior en los afectos más íntimos y privados del sujeto. En una estampa italiana, en el poema "En Florencia, en un rincón de vía San Zanobi, el tiempo parece detenido" (RHCF 85), el poeta congela la ciudad que mirara su madre "con ojos derrotados" para buscar "un minuto de paz", aunque es otra vez la lluvia -como un perseguidor implacable- quien condena las historias a "un final predecible,/ el frío en las ciudades, los charcos en la acera" (85). En "Postal de Praga" (RHCF 88-89) vuelve a ver espejada su intimidad oscura en el Moldava: "la ciudad está quieta,/ es un dolor sin dioses ni esperanza". Todo se sumerge en la neblina opresiva común a las "ciudades que tienen un rincón/ donde buscar la muerte". Invierno, frío, tormenta son el leit motiv del hablante que acompasa su existencia a "la espera", "a vivir sin rencor", a creer que "el miedo y la tristeza" pueden sostener a pesar de todo "un milagro de voces, un dolor tan amargo como el frío" (89).

\footnotetext{
11 A propósito de este poeta, Valverde publica en Seix Barral una antología suya, Después de mil balas, traducida en colaboración con Branislava Vinaver.

12 Valverde reescribe en este poema frases de una de las tres últimas cartas que envía la poeta rusa, concretamente la que manda a su amigo Nikolái Aséiev, anticipando su suicidio, que será ese 31 de agosto de 1941.

13 Mandelstam, “considerado con Anna Ajmátova uno de los máximos exponentes del movimiento poético acmeísta, derivación del simbolismo ruso y reacción contra él, apuesta por la claridad, la sencillez y la precisión" y "la descripción del entorno adquiere gran importancia" en su obra; será "torturado y encarcelado hasta morir de frío y miedo" en uno de los campos de concentración de Stalin” (García Prados, 203, 205). Señala la autora que ese último verso es tomado literalmente del autor en su poemario El que encontró una herradura, escrito en Moscú en 1923, que dice "El aire puede ser oscuro como el agua, y en él todo lo vivo nada como los peces" (García Prados, 209).
} 
También América es atravesada por este sujeto itinerante. En el norte, la serie nos presenta a "Un violinista ciego en Central Park" (RHCF 79), que no puede ver el otoño, pero que "presiente" con "la manos y el oído", las "heridas de edificios", que se escurren "en esta soledad de diecisiete/ millones de habitantes por las calles". En el sur, Buenos Aires aflora en "Un extranjero llora en la Plaza de Mayo" (RHCF 78), reiterando el inevitable vínculo de la ciudad porteña con el reclamo por la vida desaparecida en esa Plaza tan paradigmática como desoladora. "Lluvia" y "lástima", que se resuelven en incomprensión ante "tanta ruina inútil", mientras persevera la lucha por el nombre "entre el aire y la luz". Con sutileza y máxima implicitación, el lector reconoce entre líneas ese trágico juego adverbial: "alguien dice”, "nadie conoce”. Y todos somos la Plaza de Mayo con esas madres de pañuelos blancos que claman por sus hijos "desaparecidos".

El poema titulado "Una plaza" es el que mejor nos lleva al escenario de las profundas transformaciones urbanas del fin de siglo XX, donde el desdoblamiento del sujeto se bifurca en dos ciudades y dos sociedades diferentes: "Las cosas se derriban pero aparecen otras". Casas destruidas y reedificadas, plazas "llenas de escombros y de andamios". Era "otro tiempo,/ de otra ciudad y de otra vida", dos identidades colectivas y "otra gente que ignora nuestra historia". La ciudad es un ser mutante, porque "también es otro el hombre que hoy escribe" y la escribe, desde su "nostalgia, su voz y sus ideas". El pasado se puebla de voces de "otro tiempo", que retumban en el trazado de esta plaza nueva, que aún conserva "el miedo y mi costumbre de mirar hacia atrás" (RHCF 86-87).

El libro RHCF termina con un poema entrañable, "Soliloquio del olvido", que recupera el título general y da las razones del viajero que contradicen esa pulsión de fuga inicial: "El amor nunca entiende de tiempos ni ciudades,/ tampoco de razones para huir/ de una ciudad con frío". Es la ciudad-mundo, que gira a su alrededor "en constante movimiento"; es la ciudad-espejo de un alma y una conciencia que admite sus olvidos y se "acostumbra/ a vivir sin refugios ni banderas". En una íntima interlocución a sí mismo, el hablante se examina y recorre "tus recuerdos, tus justas de otros años,/ tu nostalgia y tu rabia..." para llegar a la única conclusión convincente: "No hay respuesta posible que no habite en ti mismo" (RHCF 93-94). El sujeto se reconcilia al fin con esa ciudad de la que quiso huir; porque lleva su misma piel, es una y múltiple, propia y ajena, real e imaginaria: es la ciudad con frío escrita desde su conciencia y corazón. ${ }^{14}$

La recurrencia del título "Madrugada" para varios poemas de sus diferentes libros merece una atención particular. Umbral temporal, con su aura iniciática, reapropiación heterodoxa del molde medieval de la albada, Valverde desde temprano sitúa en este momento auroral muchos de los valores y afectos más preciados, generalmente situados en las ciudades. En VF son tres los así titulados. En el primero, la madrugada sorprende al hablante "solo y sin coartada", mientras "dormía la ciudad", investida de invierno, frío y silencio. Ese "viento favorable" que da título al poemario es no obstante una falacia; lo empuja no al gozo del inicio de la jornada sino a su resignación: "El viento es favorable', me decía./ 'Ya es hora de partir hacia el naufragio" (VF

\footnotetext{
14 En palabras de Morales Lomas, la ciudad de Valverde es "un espacio donde encontrarse en ese ámbito de lo identitario", "unas veces Granada, otras Praga o Sarajevo o Moscú. Y siempre con un componente para la arquitectura vital. [...] La ciudad es también la existencia, un mundo derruido, lleno de escombros, una colectividad que nace para el encuentro y para quizá reencontrarse" (2017: 132).
} 
21). En el siguiente texto homónimo, su correlato, la noche, cierra el ciclo, situado también en la desgana y extravío de "demasiadas partidas y ciudades" (VF 22). El tercer poema así titulado (VF 23) nos remite a una escena onírica, superadora del spleen de lo real: "un lugar sin tedio ni promesas", ni ausencias ni amenazas de muerte, donde la madrugada parece inaugurar un tiempo imaginario, en una habitación "repleta de ventanas", feliz metáfora de la liberación del tiempo como cárcel en una ciudad inventada e intangible.

En RHCF son nueve los poemas titulados "Madrugada". Se entrelazan la memoria de la infancia $(46,47)$, la actualidad corporal del amor $(48,49)$ y sus partidas y ausencias $(50,52,53)$, la lucha contra el tiempo y su claudicación (51), hasta desembocar en una experiencia integradora: "madrugadas de todos" y "sin nadie", "pobres" y "en lugares fríos" (54). Una vez más, Valverde vincula esta instancia auroral a la soledad del que despierta y reconoce que "sin nadie es difícil madrugar cada día". Enlazando la serie con el título del poemario, no hay duda de que el locus crucial de este hondo sentimiento es esa "ciudad con frío", que el viajero intenta abandonar, argumentando con razones que justifican ese imaginario urbano, signado por la desolación de "la gente que huye y que sostiene/ en las manos un gesto parecido a un milagro" (RHCF 54). ${ }^{15}$

En Los ojos del pelícano (2010), el paisaje omnipresente es el marítimo y jalona las cuatro secciones, desde el mar al que van a morir los pelícanos (sección I), a "El peso del agua" (II), "Es inútil seguir la sombra de los faros" (III) y finalmente "El tacto en la arena" (IV). Toda una corporalidad natural extendida como un mapa de la experiencia subjetiva. La anécdota inicial -los pelícanos muriendo en el mar del Pacífico en San Juan del Sur, cuando intentan pescar para sobrevivir- acciona el dispositivo argumental del libro, pero encubre una metáfora de la relación del hijo con la madre, y de modo general, es emblema de los sueños hechos añicos contra la realidad que los aniquila, a pesar de la perseverancia ciega del soñador. ${ }^{16}$ De eso se trata el título del primer poema, "La caída", que excede la voluntaria muerte de esas aves del Pacífico que tanto extrañan a los turistas curiosos. ${ }^{17} \mathrm{El}$ sujeto rescata su "dignidad en el vacío" (OP 103), el amor de ese vuelo donde "el agua los engulle como al plomo". Es una caída de algún modo celebratoria, que rescata ese símbolo de su carga negativa para dotarlo de una aureola de respeto y veneración. ${ }^{18}$ Esta vez la interlocución adopta una figura de la intimidad ("a mi madre") para

\footnotetext{
15 En ID habrá todavía dos poemas más titulados "Madrugada", que reafirman este espacio temporal signado por la tristeza y la ausencia (ID 196 y 197).

16 En la contratapa del libro apunta Darío Jaramillo que: "De tanto golpear su rostro contra el océano muchos pelícanos mueren ciegos, perdidos en el horizonte. De todo eso habla este libro, del destino de los pelícanos y de cómo los sueños de la gente normal se estrellan una y otra vez contra la realidad. Lleno de imágenes deslumbrantes, de situaciones límite como la agonía y el sufrimiento, del color y el dolor de la infancia; su autor nos regala estos hermosos poemas, entrañables, muestra de piedad por los otros y despiadados con quien testimonia o recuerda" (2012, s/p).

${ }^{17}$ Vale destacar aquí la lúcida reseña que hace de este poemario Jorge Bocannera, quien enfatiza la dialéctica entre el pasado que se pierde y el presente que se difumina, "el tiempo y su hacer a destajo" (2010: 194).

18 Para Martínez Pérsico, la imagen de la caída "es la imagen-símbolo que vertebra los tres últimos poemarios de Valverde [que la] reelaboran desde perspectivas distintas pero complementarias, desde el revisionismo histórico en clave poética hasta la especulación existencial”; "está asociada, en textos bíblicos y teológicos, con la toma de conciencia [...] o con un derrumbamiento moral" y, "en un sentido más amplio, representa la muerte, el aniquilamiento físico", pero "si nos movemos al territorio de la Historia del siglo XX la palabra caída nos remite ineludiblemente al derrumbamiento de las grandes ideologías” (2017, s/p).
} 
traerla del olvido a su recuerdo. Se reproduce una escena del pasado, en una habitación, "aquella tarde" de un otoño con frío, madre e hijo tomados de la mano. ${ }^{19}$ Esta madre-pelícano no teme el golpe del agua contra el rostro, si en esa caída "salvas mi miedo con tus gestos". Y frente a "ese mar que tanto amas" realiza un salvataje milagroso: sus brazos "cubren el cuerpo de mis nueve años/ hasta tocar la orilla". El abrazo del pasado es reeditado en un presente intocado, porque en ese reencuentro "nos espera la vida" (OP 104-105). Se trata de una conmovedora elegía a la madre perdida, pero recuperada, en una caída que se convierte en ascensión: "busquemos nuestra orilla", "es hoy, no somos el pasado". 20

Las ciudades que afloran en este poemario forman parte de un mapa de "lugares que tienen una herida que sangra" ("El mar desde el Vedado", OP 121). Desde los pelícanos de San Juan del Sur a la escena de Managua, donde unos niños "sueñan con ser pelícanos/ y buscan un océano", la mirada del poeta se pasea por estos paisajes de Nicaragua, donde esos niños-pájaros "miran al cielo" con "las sucias manos pobres del desierto" (OP 106-107). En "El milagro", la mirada del hablante recorre también a los que habitan "los pinos y los cedros", "los sauces de los bosques / mientras huyen los búhos" y "las aves zancudas", o "estas piedras / que bajan por los cerros en cascadas" (OP 113-115). Es el paisaje hostil del frío otra vez, transportado a otra geografía: "no entiende este país su dolor ni su fiebre/ pero mira perplejo a sus profetas" (115).

En la III sección, el viaje del sujeto nos transporta a Europa. Primero, la interlocución se vuelca a un tú que -como señala su título "Sombras"- deambula por "un campo en Módena", después "estás en Praga" hasta susurrar en Varsovia: "Quiero volver contigo a esta ciudad" (OP 125-126). El amor es un espacio de encuentro que no requiere localización; puede atravesar distancias inmensas y se conjuga muchas veces en cifra urbana: "En un hotel de Amsterdam/ pienso que es imposible volver a las ciudades/ que son como una espada que atraviesa un deseo" (126).

Otra modulación urbana frecuente es la que está atravesada por la melancolía. Emerge de los incesantes tránsitos por las ciudades que visita el sujeto. En el Paris de "Rue de Malte" la hipálage de "días" que pasan "fatigados" y "apurados recorren las ciudades", "sus aceras burguesas/ sus horas oxidadas" no es más que un rodeo para describir el alma de esos transeúntes -el yo incluido-, que rememora un pasado perdido, vuelto "escombro" (OP 130-131). Las ciudades habitan el presente como postales de un pasado luminoso, historias con sentido, como la de "El beso" en "Viena, / 22 de febrero de 1907", donde la nieve "sirve de escondite a los amantes" (OP 133-134).

En la IV sección, la nostalgia aflora en la remembranza de "El viejo estadio" de la infancia, proyectando la fragilidad de "aquel niño/ que de mayor sería periodista" en un espacio que ha

\footnotetext{
${ }^{19}$ Es interesante observar un dato biográfico, magníficamente estilizado: se trata del recuerdo de una habitación de hospital, donde su madre estuvo ingresada un mes en coma y el hijo pasaba las noches allí escribiendo el poema. Una escena poética que da cuerpo ficcional a una escena real que documenta su autor.

${ }^{20}$ En ID el poema "Los recuerdos borrados" otra vez vuelve a esa memoria de la madre anudada a una ciudad y un tiempo específico: "Al final de la noche, lejana como infancia o amor desprevenido,/ se avista una ciudad" (ID 223). El colegio de monjas, el uniforme, ahondan la lejanía de la juventud en esta "otra mujer" que envejece, "mientras la vida avanza como madera vieja", pero supo tener "paciencia de derrota acostumbrada,/ y el miedo a la desgracia de tres hijos" (ID 224). En ese mismo tenor puede leerse el poema "Conversión en sombra" (ID 229).
} 
quedado en el pasado, "un tiempo detenido [que] es mejor que el futuro" (OP 146-147). Nostalgia de una experiencia que lo hermana con su abuelo en el poema titulado "El último minuto" y hace de ese lugar tangible, donde el futbol reúne pasión y desvarío, una forma de homenajear la memoria de su infancia: "aquellos dos asientos/ sobre la piedra fría del invierno [...]/ son el lugar más cálido posible" (OP 157-158). Un refugio diminuto dentro del desamparo urbano. Un lugar que no sangra y lo salva de la herida del tiempo que todo lo corroe.

El periplo histórico en cifra urbana continúa en este libro. ${ }^{21}$ Su poesía da cuenta de la "historia desde abajo" (bistory from below),22 la que se vive en las aceras y en los domicilios particulares, más que en los archivos y documentos oficiales. Ciudades como Sarajevo aparecen otra vez, como paradas en el camino de un viajero que no es mero turista, ya que comulga con sus calles y parques, y recuerda su historia de "disparos" que llenaron "de huérfanos las plazas" ("Verano en Sarajevo", OP 149-150). ${ }^{23}$ Sin altisonancia, su hablante denuncia que "se estrelló la miseria en las paredes", "no existe periferia en Sarajevo", porque "ha bajado el infierno a esta ciudad". Otro eje espacial lo representa Oriente, desde Damasco con "las dunas del desierto" y "bandadas de palomas", semejantes al sujeto que busca "una ciudad donde no estorbe el viento" (OP 151), ${ }^{24}$ hasta la "noche en Palestina", donde resulta "peligroso este paisaje" y "sangra el Mar Muerto aparentando calma" (OP 152-153). Ejes inflamables en el concierto bélico de un planeta siempre en llamas, que la mirada solidaria del poeta escudriña desde su posición doméstica y privada. 25

\footnotetext{
${ }^{21}$ Afirma Morales Lomas que este "es un poemario para la elegía y la memoria que se unen en múltiples situaciones vitales a medida que el poeta va recorriendo el mundo y visitando ciudades: París, Damasco, Managua, Sarajevo [...]. No es solo la voz doliente del poeta ante el dolor propio sino también ante el dolor del mundo en ese camino hacia la otredad [...]. Junto a esta singladura el recorrido por las ciudades puede ser un buen momento para ahondar en la
} incertidumbre" (2017:133).

22 En un estudio sobre las formas de vincular la Historia con las historias (bistory frente a stories), a propósito de la poesía de Luis García Montero, argumentaba yo hace años que "la poesía tiene su forma de contar la historia: a través de la escritura -gesto privado del poeta- se escribe una memoria compartida -pública y colectiva-. Pero esta escritura es también una forma de hacer pública una memoria enunciada por un individuo (y por tanto privada). Públicoprivado, social-individual son términos de una dialéctica que la poesía actual trata de demoler" y se vincula con "lo que algunas corrientes historiográficas han llamado microbistorias, constituyendo una tendencia formalmente denominada history from below (la historia desde abajo [Burke 1996])". (Scarano 2004: 90)

${ }^{23}$ El hecho histórico que dispara el poema dará lugar a la I Guerra mundial: el 28 de junio de 1914, el sucesor al trono del Imperio Austro-húngaro y comandante en jefe del Ejército Imperial, el archiduque Francisco Fernando, se dirige a Sarajevo, recién incorporada al imperio, y es asesinado por un joven estudiante nacionalista serbio.

${ }^{24}$ Rememoración, según el propio Valverde, de una visita que hizo con Francisco Ayala a su casa de la infancia en el Albaicín granadino, llena de animales domésticos y un preciado palomar. Se trata de un recuerdo que el poeta fusiona con una visita posterior a la ciudad de Damasco donde conoció a un hombre que cuidaba palomas (2016, s/p).

25 Cabe destacar que en otro trabajo hemos analizado la configuración de este yo doliente y extrañado, afirmando que: "La experiencia de ajenidad enfrenta al yo con el enemigo, el acosador, en Los ojos del pelícano [...]: «Dentro de este poema pasa un lobo». El peligro del afuera, animalizado en el paso sigiloso de ese lobo que «recorre una ciudad / que miró confiada hacia el futuro», se trueca en enemigo íntimo: «en este poema espera un lobo/ que ha venido a buscarme». El otro es también yo, y yo soy ese extraño que me acosa: «Aunque intente estar quieto y no hacer ruido / salta por las palabras un recuerdo/ que me arranca un aullido y me devora». Del mismo modo, en «El bosque», este se vuelve metáfora del peligro. Es la espesura, lo desconocido, ante el cual la voz, «tan rota y tan cobarde», no logra sobreponerse. Pero es también un fatal sucedáneo del yo: «es mejor estar quieto [...] / aunque el bosque sea yo y alguien huya de mí». Dos autorretratos elusivos, que distancian mediante correlatos (un lobo, el bosque) la disyuntiva del sujeto ante su propia extranjería" (Scarano 2017: 21-22). 
El último poemario, La insistencia del daño, está dividido en cuatro secciones que jalonan un itinerario existencial desplegado como mapa geográfico, cartografía del dolor y travesía comunitaria. Quizás es su libro más laureado, el que, como señala Nathalie Handal, "con un lenguaje cincelado, crea lírica de las ruinas. Su objeto es la justicia, la traición de la memoria, la persistencia de la mancha humana", "dejándonos versos grabados en la conciencia y un misterio que trasciende el dolor" (2014, s/p), y al que Piedad Bonnet no duda en describir como un poemario que "con sus poderosas imágenes y con la fuerza emotiva que siempre anida en la verdadera poesía", exhibe con desgarro cómo "el tiempo es la materia de la que estamos hechos". ${ }^{26}$ Sin duda es un "recorrido sentimental por el dolor (el daño del título) desde esa infección general y ceguera", "que se revela en ciudades que sirven de acomodo a un viaje sentimental" y que son "un pretexto para abordar la temática de la pérdida" (Morales Lomas 2017: 134-135).

Viaje y mapa, camino y caminante, funcionan como lexías privilegiadas y recurrentes en su discurso, emplazadas en una dialéctica entre el yo y los otros, como personajes de un relato que traza una herida compartida. En la primera sección titulada "Cruces y sombras", la caída forma parte de la identidad del personaje que deambula por espacios mixtos, ciudades borrosas, naturalezas espectrales. Figuraciones como la del "Caminante sobre un mar de niebla" muestran la textura de un flâneur simbólico, que atraviesa la vida entre el "vértigo" y la "angustia", intuyendo "la caída", ese "salto que sucede a los fracasos" (ID 173).

Varias microhistorias se entrelazan con personajes históricos reales, fusionando coordenadas de tiempo y espacio. "La joven de Scarborough" es "Ana Brönte 1820-1849)", que muere de tuberculosis, pero el poeta la atrapa en su mirada hacia el mar, el agua y su espuma, soñando una "caída que la libere de su agonía" (ID 168-169). Más crudo, el retrato en el poema "Ratko Mladić conversa con la muerte" nos confronta con los horrores de este general actuante en la guerra de Bosnia (1992-1995), quien fuera denominado el "carnicero de los Balcanes", enfrentado cara a cara con la muerte, mientras "se aleja de los vivos" (ID 170-172). Detenido en Serbia en 2011 tras dieciséis años de fuga, fue condenado a cadena perpetua por el Tribunal Penal Internacional para la antigua Yugoslavia (TPIY) por crímenes de guerra y de lesa humanidad. ${ }^{27}$

El poema dedicado al mexicano Alí Calderón, poeta compañero del grupo Poesía ante la incertidumbre, titulado "Con los ojos abiertos caminas por la muerte" (ID 176-179), los recrea en un paseo juntos por Bolivia, "en la última quebrada de los Andes", donde de manera elusiva se desarrolla una trama imaginaria que ubica entre los pobladores de ese "valle del dolor" a "alguien que se llama Ernesto" (evitando la alusión directa al Che Guevara, capturado y ejecutado por

\footnotetext{
${ }^{26}$ Véanse estas referencias de Handal y Bonnet en la contraportada del libro ID (recogidas además en el sitio de internet del autor), junto con muchas otras citas (de Jorge Galán, de Benjamín Prado, de Luis García Montero), transcriptas a su vez en el número 4 de la revista Círculo de Poesía (2014).

27 “Culpable de los cargos de exterminación, asesinato, persecución, terror, secuestro, deportación, desplazamiento forzoso, actos inhumanos y ataques ilegales contra civiles, por impedir la entrada de ayuda humanitaria en Sarajevo y Sbrenica, por su política de limpieza étnica, por secuestrar cascos azules de la ONU que fueron usados como escudos humanos para evitar bombardeos de la OTAN, por diseminar propaganda falsa para confundir a la comunidad internacional" (Martínez Pérsico, 2017, s/p).
} 
el Ejército boliviano el 9 de octubre de 1967).28 La familiarización del líder por el uso sólo del nombre de pila y su retrato, inmerso en un paisaje "donde pastan el hambre y la pobreza", coagula dos tiempos (el de su muerte y el de la visita de los dos poetas) en la memoria colectiva que repite ese nombre-ícono: "Dicen que eres un muerto de los que nunca mueren". Su mirada desde un más allá atraviesa el dolor del acá y su presente de fiebre y tuberculosis, de enfermos en el Hospital de Malta, porque "nada puede callarte" ni siquiera "aquella tarde de mil novecientos sesenta y siete". Otra vez un tiempo y un espacio se cruzan para retratar otra estampa de injusticia y dolor histórico. Su agonía, su derrota final, sus últimas horas en el hospital desfilan ante nuestros ojos y ante los de los personajes que lo acompañan en ese viaje espectral y repiten su nombre como un mantra, "como quien busca alivio en medio del dolor", para verlo "morir con los ojos abiertos" (ID 179).

Por último, siguiendo esta galería de personajes signados por la muerte, otro poema retrata al poeta bosnio Izet Sarajlic (1930-2002),29 deambulando en Ilidza, reiterando la estampa que presentara de él en una de las "Cinco elegías para un siglo" (RHCF 81). Este nuevo poema, titulado "Izet Sarajlic cruza una puerta que conduce al dolor", recrea el paseo desorientado de uno de sus vecinos, Vlado, quien "sale a buscar su bala cada tarde", sin atreverse a arrojarse él mismo por elección a la muerte (ID 180-181). Y se cruza con la mirada de Izet, que contempla "la forma en que la lluvia/ es una puerta abierta hacia el dolor". El poeta bosnio lo ve cada día saliendo a pasear por Sarajevo, esperando que un francotirador le dispare. Pero nadie lo hace, porque en Sarajevo muere quien no quiere morir y la muerte no alcanza a Vlado, incapaz de suicidarse. No hay casa propia adonde volver en esta ciudad devastada por la guerra y "el sonido de aviones dibuja otro país", "mientras, en las colinas,/ los francotiradores/ van a ser la destreza de la muerte" y su impacto "un silbido que rompa los cristales, / un balcón al vacío". La estampa urbana está distorsionada en estos poemas históricos, que capturan lo doméstico en clave de

\footnotetext{
28 Valverde viajó a Bolivia en 2013 junto al mexicano Alí Calderón, invitado por el poeta Gabriel Chávez a Santa Cruz de la Sierra, su ciudad. Allí decidieron alquilar un coche para ir a La Higuera, a más de 240 kilómetros: "La Higuera está en el final de la cordillera de Los Andes. Al borde de un precipicio. Es posiblemente el último lugar del mundo, un lugar al que no habría querido ir nadie. [...] Vallegrande es un pueblo a $60 \mathrm{~km}$ de La Higuera. Es el más grande de la zona. Cuando mataron al Che subieron su cuerpo a un helicóptero y lo llevaron a la lavandería del hospital de Vallegrande. Allí mostraron su cadáver y allí fueron tomadas esas fotografías del cadáver del Che con los ojos abiertos", explica Valverde en una entrevista del 2 de enero de 2016, consignada en la Tesis doctoral de Nieves García Prados (2016: 65). Precisamente en ese morir con los ojos abiertos, "en ese hecho simbólico está el resistirse a la muerte, también la esperanza o incluso el ver más allá. El final invita precisamente a la reflexión al lector, que sentirá lo que le dicte su experiencia personal" (2016: 70).

${ }^{29}$ En la revista Circulo de poesía aparece un adelanto de sus poemas en el libro -con traducción y prólogo de Fernando Valverde- titulado Sarajevo (editado en 2013 por Valparaíso Ediciones). Allí explica: "Es la colección más completa publicada en español de sus poemas escritos durante y sobre la Segunda Guerra Mundial, en la que los camisas negras fusilaron a su hermano Ešo. El cerco de Sarajevo está considerado como el mayor de la historia de la guerra moderna. Siete veces más largo que el de Stalingrado, durante sus 1336 días el poeta bosnio permaneció en la ciudad, marcados por sucesos como la muerte de sus dos hermanas, a las que tuvo que enterrar de forma clandestina con sus propias manos, la traición de muchos de sus amigos serbios, que disparaban sobre la ciudad desde las colinas (entre ellos Radovan Karadžić), y el sufrimiento de los santos de Sarajevo". Para Valverde, "la poesía clara y sencilla de Sarajlić es el mayor testimonio poético de la Guerra de Bosnia. Salpicados de una fina ironía, de un conmovedor amor por los otros y de una resignación heroica, sus poemas son la narración desnuda de su dolor, símbolo de la tragedia de todo un pueblo" (Valverde, 2013, s/p).
} 
tragedia, pero sin grandilocuencia ni efectismo: "en la calle la gente regresa del mercado/ y corre con sus bolsas", con el terror y la violencia agazapada amenazándolos.

La siguiente sección, titulada "El viaje del mundo", acentúa el carácter itinerante del sujeto, que se mueve entre geografías interiores y cartografías territoriales. 30 Puede ser a veces un viaje a la memoria de la infancia, que superpone el pasado infantil de un verano en Granada, con el presente del adulto en Budapest, en "La orilla del precipicio". Esa frontera delgada encuentra en la metáfora del borde su mejor emblema, sellado por la nostalgia de un tiempo-espacio detenido, que nunca puede retornar igual: "no existe aquel lugar en el que te has quedado" (ID 190-191). La búsqueda del otro, del yo -su alter ego-, de la madre perdida o el amor pasado, de su niñez granadina, es el trasfondo que contempla el adulto desde otro "aquí", que no es "allî", alterando con los deícticos la precisión espacio-temporal. En su presente "empieza a amanecer sobre el Danubio" y "despierta Budapest y despiertas en ella". La máxima declaración de este proceso de interiorización del espacio se concentra en estos paradigmáticos versos: "Ya no es una ciudad, es un rincón de ti". La ciudad del recuerdo no ocupa un lugar fuera del yo: "Yo quisiera buscarte por todas las ciudades, / pero siempre regreso/ porque en aquella orilla no hay muerte que celebre/ el tacto de tu infancia...” (ID 191).

Esta dualidad se articula muchas veces en desdoblamientos del yo o interlocuciones a un tú del pasado añorado, que reformula la identidad en términos espaciales: "Yo he dejado un camino que conduce hacia ti", aunque se confiese "cobarde caminante que prefiere/ la ciudad de las horas detenidas..." (ID 192-193). Otras veces, con la adopción de un molde, como el del "Nocturno" tan prestigioso en el romanticismo, la reflexión desemboca en una escena urbana. Tal en "Nocturno de Mala Strana (Poema de amor)" que describe Praga con "su viejo cementerio", "las torres grises", "el barro de los ríos" (ID 195), con gente que corre y "se esconde en los portales", mientras "un silencio de plástico/ golpea los carteles y las lápidas". Ciudad-cementerio, en "esta ciudad de esquinas invisibles,/ de llantos que no pueden contenerse", todos comulgan con el sentimiento del hablante: "ya todo el mundo llora el amor que perdí". El último poema de la sección, titulado "Muelles abandonados", nos transporta a Lisboa, donde "cruza la soledad la muchedumbre/ hablando en otro idioma" y la ciudad se vuelve el locus privilegiado para hablar de amor: "tu piel está en mí como un tejado/ contiene una ciudad" (ID 200).

En la tercera sección, "La tristeza en los mapas", se agudiza este tono elegíaco en clave espacial. Vuelve a presentarnos el emblema del mapa como espejo interior, ya que su signo de identidad es "la tristeza", una emoción humana que profundiza el itinerario de daño y devastación que viene proponiendo el poemario. Una peculiaridad de los títulos es que se presentan entre paréntesis y señalan en su mayoría lugares específicos. Es una forma de imponer un tono menor, aclaratorio, sucedáneo, de indicación o guía preliminar, una especie de punteo geográfico en un mapa discursivo. Se alternan textos brevísimos que analizan sentimientos en clave histórica, casi

\footnotetext{
30 Esta sección se abre con uno de sus poemas más conocidos-quizás el más logrado de su obra- titulado "Celia", que ganara el premio Antonio Machado, conocido como el premio del Tren. No lo incluyo en este recorrido crítico porque representa un momento detenido en el tiempo, como si estuviera suspendido en un no-lugar: el del nacimiento de Celia. Si hay viaje es hacia el futuro imaginario e imaginado por el hablante para esa criatura, como los sueños que "son parte de nosotros/ como un embarcadero es un viaje" (ID 189).
} 
siempre de modo implícito, como en "(El Salvador)": "Hoy sé que la esperanza/ es el miedo/ con los ojos vendados" (ID 205). O en "(Puebla)", México, donde reescribe el epígrafe de Luis Rosales que encabeza la sección: "Pienso que la tristeza/ es la tierra del hombre" (ID 207).31

Y coexisten con textos más largos pero igualmente metafóricos, donde el lugar se convierte en cifra de una emoción, generalmente asociada con el desamparo y la muerte. Así en "(Potocari)" se adensa la imagen de "los muertos" que "saben el final del camino" y "siempre dejan un silencio apremiante" (ID 208). O en "(Bogotá)", donde "todas las calles llevan hacia el norte" y "todos los mapas buscan un regreso" (ID 209). En "(Ruina de Toniná, Chiapas)" también la muerte es señora de ese "nido de águilas" (ID 210), y en "(Plaza Sintagma, Atenas)" perros, motos y coches concentran "la desesperación/ que es fuego y alambradas", frente a un transeúnte que "baja la vista" y busca "pasar inadvertido" (ID 212).

Pero es quizás "(Playa de San Cristóbal)” el poema que abre con una sentencia el núcleo fuerte de esta visión interiorizada del espacio, cuando afirma: "Podéis mirar el mundo a través de mi llanto" (ID 213-214). El mapa es pues el propio cuerpo en comunión con todos aquellos, aunque desconocidos, que en lugares cercanos o remotos, sufren y se enfrentan al dolor y al daño sistemático del poder. Por eso el poema "(Campo de los mirlos)" (significado de la palabra Kosovo) nos presenta no ya un paisaje ameno, sino bélico, a pesar de ser considerado sagrado por los serbios, porque es donde murió el príncipe serbio Lazar derrotado por el Imperio Otomano en la batalla de Kosovo Polje, y con él desapareció el reino medieval de Serbia (origen de todo el conflicto de los Balcanes). ${ }^{32}$ Ese espacio desnuda "la ruina de la guerra [que] bebe el amanecer" con "la inercia del odio,/ el espanto que corre hacia las balas/ y la sangre que crece en manantiales" (ID 215).

Por fin, la ciudad devastada por la muerte logra una máxima condensación en la concentrada evocación de un muerto más, en el poema "(Agra)", ciudad situada a orillas del río Yamuna, en el estado de Uttar Pradesh, en la India, que cierra esta sección. Contrasta la soledad del cadáver abandonado, indiferente para las miradas de la multitud anónima, cifra de la injusticia que clama en silencio sin voces que la denuncien:

Hay un cuerpo tirado entre la muchedumbre.

Poco vale la vida

cuando no queda nada que perder,

apenas un zarpazo,

una herida que sea el prodigio o la grieta,

el pacto de la sangre con el miedo.

(ID 216)

Finalmente, la cuarta sección, titulada "La luz no llegará viva a mañana" (ID 221-222) (dedicado al poeta Benjamín Prado, miembro de la llamada "poesía de la experiencia" en la

\footnotetext{
31 En palabras de Luis Rosales:'La tristeza es anterior al hombre, es la tierra del hombre”.

32 Detalla Nieves García Prados a propósito de este poema que “otro 28 de junio marcado para siempre en la historia de los Balcanes es el del año 1389. Ese día, en el mismo lugar en el que hoy se encuentra la torre de Gazimestan (a las afueras de Prístina), se libró la Batalla de Kosovo, un acontecimiento histórico sin demasiada trascendencia que iba a convertirse en simbólico, conocido como la batalla del Campo de los Mirlos” (224).
} 
década del 90), parece coronar una derrota, pues plantea la densidad del "daño" tematizado. Como estos poetas que lo anteceden, junto con su maestro Luis García Montero, Valverde se plantea también un análisis histórico de los sentimientos, en la senda del Juan de Mairena machadiano. La intimidad es un territorio que pone a prueba las tensiones del campo de lo público y su intersección con lo privado. El poema que abre esta última sección titulado "El daño" es un magnífico ejemplo de este tono especulativo, que ahonda la meditación desde un plural gramatical que nos involucra como sociedad. ¿Cómo empezó este daño y por qué? La respuesta es un intento de comprensión desde una perspectiva social y comunitaria:

Porque tal vez la vida nos dio todo al principio

y seguimos buscando

un camino que lleve a ese lugar

Porque tal vez la vida no nos perteneció

y se fue consumiendo

como todas las cosas que hemos creído nuestras

y son parte del daño

que dibuja las líneas de la historia

derribando ciudades con sus muros.

(ID 221)

Prevalece un halo de resignación y culpa frente a otros caminos alternativos que, sin embargo, no pudieron triunfar sobre el daño: "Y de haberlo sabido/ habríamos juntado nuestras manos", "habríamos mordido nuestros labios/ sangrando en el amor". Oración, amor, solidaridad, renuncia al individualismo, para contrarrestar el daño y "dejar visibles las heridas", nada finalmente parece salvar a nuestra generación y, por extensión, a nuestra especie: "Es todo tan inmenso que no cabe en el llanto/ y el dolor nos observa desde fuera” (ID 222).

El poema que cierra el libro y su poesía reunida se parece a una claudicación, aunque esconde un desafío existencial, cifrado en metáforas lumínicas: "Es la debilidad que hay en la luz/ un principio del fuego" (ID 232-233). Existe un fuego que quema desde dentro, "que sucede en las sombras/ y habita en el futuro desde el llanto". Es emblema del "miedo atroz/ que no deja dormir" y devora todo: la nostalgia, el amor, la esperanza, la piedad, incluso "el canto que espantaba los diluvios/ porque el cielo escuchaba". Pero hay subterfugios y estrategias para sortear las sombras: "Este enjambre de luces son las sombras/ evitando una noche aún mayor". El cierre del texto parece conducir al fracaso y a la resignación individual: "y no tengo ya fuerzas/ ni las ganas de entrar en un atardecer" (ID 233).

Pero nunca olvidemos que esta poesía se forjó en "madrugadas" sucesivas, se templó en ciudades con vocación de llanto, para las que fue posible encontrar palabras que las sostengan en contra de ese daño. Como "El terremoto" que asola la ciudad y la vuelve "tan simple, tan frágil,/ tan vulnerable al fin" (ID 227-228), el sujeto apuesta a construir consensos porque "no estaremos solos hasta que hayamos muerto". Y aunque "se mueven las montañas" y "vuelcan campanarios" y "nos persiga el dolor/ como barro pegado en los zapatos", existen salidas si "al tropezar calculo la distancia/ que existe entre los pies y la felicidad" (ID 228).

Para Valverde, la poesía puede establecer un compromiso humano solidario por fuera de las consignas y banderías cerradas. Como concluye Jorge Boccanera, "lejos de cualquier efectismo, 
los apuntes del poeta sobre cualquier geografía lejana acercan situaciones, seres y paisajes en su cotidianeidad, vale decir: nos son familiares en su fondo humano" (195). Valverde da testimonio de estas ciudades devastadas, de estos hombres sin salida, refugiados, perseguidos, exiliados, suicidados: una sociedad rota donde la memoria histórica hila micro-relatos de derrotas tan privadas como públicas. Pero en la herida ajena se reconocen las cicatrices propias. Esa es su apuesta ética y poética, la que magistralmente resumen estos iluminadores versos, que expresan su búsqueda incesante de "un paisaje que pueda sostener/ dentro de algún poema" (RHCF 80). Y lo explica de manera inmejorable en su Prólogo a esta Poesía reunida, con el que concluimos:

Traté de ser testigo de la herida que el mundo comparte, del sufrimiento que nos iguala. Si la poesía puede contribuir a un mundo mejor es porque nos ayuda a comprender el dolor de los otros [...]. En medio de ese viaje, entre la luz del mundo y sus sombras, entre la belleza y el dolor, estaba la poesía. Pocas veces pude tocarla, pero cuando me rozó fue un milagro... (2016: 12-13) 


\section{BIBLIOGRAFÍA}

BoccanerA, Jorge. "Entre el furor y la nostalgia". Reseña de Los ojos del pelícano. Cuadernos Hispanoamericanos 721-722 (julio-agosto 2010): 193-197.

Bonnet, Piedad. Reseña a La insistencia del daño. Círculo de poesía 4 (2014).

Calderón, Alí y otros (2011). "Defensa de la poesía", en Poesía ante la incertidumbre. Antología de nuevos poetas en español. Madrid: Visor.

CALDERón, Alí y otros "Poesía ante la incertidumbre. Un viaje a la esencia". Los Torreones. Revista de poesía 1 (2012): 98-102.

BuRKE, Peter (ed.) (1996). Formas de hacer historia. Madrid: Alianza.

De Certeau, Michel ([1980] 1996). La invención de lo cotidiano: Artes de hacer. México: Iberoamericana.

ESPINOSA, Santiago (2016). "Una aventura transatlántica. Poetas y poesía ante la incertidumbre". SÁnCHeZ GARCíA, Remedios y otros, Palabra heredada en el tiempo. Tendencias y estéticas en la poesía española contemporánea (1980-2015). Barcelona: Akal: 315-328.

GARCÍA Prados, Nieves (2016). "La realidad social en la lírica contemporánea: el grupo 'poesía ante la incertidumbre', la crónica periodística y la educación literaria”. Tesis doctoral, Universidad de Almería.

Gorelik, Adrián (2002), "Ciudad". Altamirano, Carlos (ed.). Términos críticos de sociología de la cultura. Buenos Aires: Paidós: 12-21.

Handal, Nathalie. Reseña a La insistencia del daño. Círculo de poesía 4 (2014).

Jaramillo, Darío. Reseña a Los ojos del pelícano. (2012).

Lotman, Yuri (1996). Semiosfera I. Semiótica de la cultura y del texto. Valencia: Frónesis.

MARTíneZ, José Enrique. “Un puente entre dos orillas”. Reseña de Poesía (1997-2017) de Fernando Valverde (19/03/2017).

MARTínez PÉrSICO, Marisa. "Del poeta y el asombro. La «lírica de las ruinas» de Fernando Valverde". Los diablos azules 89 (15 de diciembre de 2017).

Morales Lomas, Francisco. "La poesía de Fernando Valverde (1997-2017)”. Poéticas, año II, 6 (2017): 127-135.

SÁNCHEZ GARCíA, Remedios (2015). "El canon abierto". GEIST, Anthony y SÁnCHEZ GARCÍA, R. (eds.). El canon abierto. Última poesía en español (1970-1985). Madrid: Visor: 9-95.

SÁnChez García, Remedios (coord.) (2016). Palabra heredada en el tiempo. Tendencias y estéticas en la poesía española contemporánea (1980-2015). Barcelona: Akal.

SARriá, José. "Fernando Valverde, la insistencia del daño". Entre Ríos 24-25 (otoño-invierno 2015): 23-27. 
SCARANO, Laura. "Ciudades escritas (palabras cómplices)". Revista del CELEHIS, año 8, 10 (1999): 207-233.

SCARANO, Laura (2004)."Las palabras preguntan por su casa". La poesía de Luis García Montero. Madrid: Visor.

SCARANO, Laura (2016). "Fragmentos de incertidumbre: Sobre el (des)concierto de las antologías poéticas" en Sánchez García, Remedios y otros (eds), Palabra heredada en el tiempo. Tendencias y estéticas en la poesía española contemporánea (1980-2015). Barcelona: Akal: 267-277.

SCARANO, Laura. "Variaciones sobre el autorretrato en la poesía última". Versants 64: 3 (2017): 13-23.

SGRISCIA, Alessio. "Una poetica d'autore. Traduzione e commento di tre poesie tratte da «Gli occhi del pellicano» e «Ragioni per fuggire da una fredda città» di Fernando Valverde". Cuadernos del Hipogrifo. 5 (2016): 1-14.

VAlVERDE, Fernando. “La casa del joven Francisco Ayala”. El País (2016).

Valverde, Fernando (ed.). "Sobre Sarajevo de Izet Sarajlic”. Círculo de poesía (2013): http:// circulodepoesia.com/2013/02/izet-sarajlic-poeta-bosnio-en-valparaiso-ediciones.

VALVERDE, Fernando (2016). Poesía (1997-2017). Madrid: Visor.

VALVERDE, Fernando. Entrevista "La poesía es patrimonio de todos, no es un lenguaje cerrado de intelectuales”. Ideal (2017).

VALVERDE, Fernando. Sitio del autor. 